\title{
Hemşireler Trakeostomili Hastaların Bakımını Ne Kadar Biliyor? Nitel Bir Çalışma
}

\author{
How Much Do Nurses Know About the Care of Patients with \\ Tracheostomy? A Qualitative Study
}

Yasemin Altınbaş ${ }^{1}$, (iD) Türkan Karaca²

${ }^{1}$ Dr. Öğr. Üyesi, Adıyaman Üniversitesi Sağlık Bilimleri Fakültesi, Hemşirelik Bölümü, Cerrahi Hastalıklar Hemşireliği Anabilim Dalı, Adıyaman, Türkiye

${ }^{2}$ Doç.,Dr., Adıyaman Üniversitesi Sağlık Bilimleri Fakültesi, Hemşirelik Bölümü, Hemşirelik Esasları Anabilim Dalı, Adıyaman, Türkiye

Sorumlu Yazar: Yasemin Altinbas, Dr. Öğr. Üyesi, Adıyaman Üniversitesi Sağlık Bilimleri Fakültesi, Hemşirelik Bölümü, Cerrahi Hastalıklar Hemşireliği Anabilim Dall, Adıyaman, Türkiye E-mail: altinbasyasemin@gmail.com Telefon: 041622338 00-4620.

Başvuru Tarihi: 11.02.2021 Kabul Tarihi: 19.04.2021 Yayınlanma Tarihi: 25.06.2021

Attf iç̧in: Yasemin Altınbaş, Hemşireler Trakeostomil Hastaların Bakımını Ne Kadar Biliyor? Nitel Bir Çalışma, 2021;5(2):72-78

\section{Öz}

Amaç: $\mathrm{Bu}$ çalışma yoğun bakım hemşirelerinin trakeostomili hasta bakımına ilişkin uygulamalarını belirlemek için yapılmıştır. Gereç ve Yöntemler: Nitel tipteki araştırma Ekim-Kasım 2019 tarihleri arasında Güneydoğu Anadolu Bölgesi'ndeki bir ilde yer alan bir Üniversite Hastanesi'nin Yoğun Bakım Ünitesi'nin 15 hemşiresi ile gerçekleştirilmiştir. Veriler tanıtıcı bilgi formu ve yarı yapılandırımış görüşme formu kullanılarak toplanmıştır. Veriler, Giorgi'nin fenomenolojik yöntem analizi kullanılarak 4 aşamada değerlendirilmiştir. Bulgular: Katılımcılarınyaşları25-42aralığında, 10’u kadın, yoğun bakım hemşiresiolarakçalışmayılı 1-15yıl olup, tüm katılımcıların lisans mezunu olduğu, trakeostomili hastaların bakımı ile ilgili eğitim aldığı ve hasta güvenliği ile ilgili bir yayını/web sayfasını düzenli olarak takip etmediği görülmüştür. Kathlımcıların trakeostomili hasta bakımına ilişkin görüşleri 2 ana tema ve 5 alt temadan oluşmaktadır. Ana temalar 1. Trakeostomili Hastanın Bakım Uygulamaları ve 2. Bakım Sırasında Yaşanan Sorunlar ve Çözüm Önerileri'dir. Trakeostomili Hastanın Bakım Uygulamaları ana teması Protokoller, Trakeostomi Öncesi Hasta Bakımı ve Trakeostomi Sonrası Hasta Bakımı olmak üzere 3 alt temadan oluşmaktadır. Bakım Sırasında Yaşanan Sorunlar ve Çözüm Önerileri ana teması Sorun Yaratan Durumlar ve Bakımı Geliştirmeye Yönelik Öneriler olmak üzere 2 alt temadan oluşmaktadır. Sonuç: Hemşirelerin trakeostomili hastanın bakımına ilişkin bilgilerinin temel düzeyde yeterli olup bakım uygulamalarının fizyolojik gereksinimler ile sınırlı kaldığı; hemşirelerin hastanın psikolojik gereksinimlerinin farkında oldukları ancak bu konu ile ilgili hemşirelik uygulamalarının ya hiç yapılmadığı ya da yetersiz kaldığı belirlenmiştir.

Anahtar Kelimeler: hemşire; trakeostomi; hasta bakımı; nitel araştırma Aim: This study was conducted to determine the practices of
intensive care nurses regarding patient care with tracheostomy. Material and Method: A qualitative type research was carried out with 15 nurses of the Intensive Care Unit of a University Hospital located in a province in the Southeastern Anatolia Region between October-November 2019. Data were collected using an introductory information form and a semi-structured interview form. The data were evaluated in 4 stages using Giorgi's phenomenological method analysis. Results: It was observed that the age of the participants is between 25-42, 10 of them are women, the working year as an intensive care nurse is 1-15 years, all the participants were undergraduate, received training on the care of patients with tracheostomy, and did not regularly follow a publication/web page on patient safety. Participants'viewson patientcare with tracheostomyconsist of 2 main themes and 5 sub-themes. Main themes are Care Practices of Patient with Tracheostomy and Problems Encountered During Care and Solution Suggestions. The main theme of Patient Care Practices with Tracheostomy is Protocols, Pre-Tracheostomy Patient Care and Post Tracheostomy Patient Care. Problems Encountered During Care and Solution Suggestions consist of 2 subthemes, the main theme of which is Problematic Situations and Suggestions for Improving Care. Conclusion: It was determined that nurses' knowledge of the care of patients with tracheostomy is sufficient at a basic level and care practices are limited to physiological needs; nurses were aware of the psychological needs of the patient, but nursing practices related to this issue were either not performed at all or were inadequate.

Keywords: nurse; tracheostomy; patient care; qualitative research 
Trakeostomi, hava yolu açıklığını sağlamak amacıyla trakeanın ön duvarında 3. veya 4. kıkırdak halka hizasında açıklık oluşması için yapılan cerrahi işlem olarak tanımlanır ve bilinen en eski hayat kurtarıcı yöntem olarak kabul edilir $(1,2)$. Trakeostomi uygulanan hasta sayısında tüm dünyada artı̧ görülmektedir (3-5). Ülkemizde ulusal düzeyde trakeostomili hastaların sayısına ilişkin yapılan çalışmalara rastlanmamakla beraber, İngiltere'de yoğun bakım ünitelerinde her üç hastadan birine trakeostomi açıldığı ve yoğun bakım ünitelerinde yıllık 50-200 hastaya trakeostomi işlemi uygulandığı bildirilmiştir (5).

Trakeostomi hava yolu açıklığını sağlamak gibi yaşamsal bir öneme sahip olmasına rağmen, özellikle trakeostomili hastalar trakeostomiye bağlı pek çok sorunla (pnömotoraks, apne, tüpün yanlış yerleşimi, peristomal cilt problemleri, trakeal stenoz, trakeoözefajial fistül ve enfeksiyon, hemoroji ve hava yolu tıkanıklığı) karşı karşıya kalmaktadır (6-8). Özellikle yoğun bakımda yatan ve farklı kronik hastalıklara sahip hastalara bakım veren hemşireler için trakeostomi bakımı oldukça zorlu bir süreçtir. Yaşanabilecek sorunların önlenmesi için trakeostomi işleminden sonra hastaların bakım süreci; yeterli ve dengeli beslenmeyi, iletişim kurabilmeyi, aspirasyonu, kanül temizliğini, cuff yönetimini, stoma bakımı ve pansumanını kapsamalıdır (9-11). Trakeostomili hastanın hemşirelik bakımında öncelikli hedef hastalarda hava yolu açıklığını değerlendirmek ve sürdürmektir. Hava yolu açıklığı trakeostomi gibi yapay bir yol oluşturularak sağlandığında hemşirelerin bu işlemlerin endikasyonlarına, komplikasyonlarına ve bakımına dair tüm bilgilere sahip olması yaşamsal öneme sahiptir (12,13). Literatürde, hemşirelerin trakeostomili hasta bakımının yaşamsal önemini bilmesine rağmen bu konuya ilişkin yeterli bilgi ve beceriye sahip olmadıklarını belirleyen çalışmalar bulunmaktadır (1416). McDonough ve arkadaşları (2016) yaptıkları çalışmada trakeostomili hasta bakımına ilişkin hemşirelerin teorik bilgilerinin yetersiz olduğunu ve uygulama becerilerinin istendik düzeyde olmadığını bildirmekle beraber hemşirelerin en çok trakeostomili hastada acil girişim gerektiren durumların yönetiminde sorun yaşadıklarını vurgulamaktadır (14). Türkiye'de trakeostomili hastalara bakım veren hemşirelerin trakeostomi bakımına yönelik bilgi düzeylerinin incelendiği bir çalışmada, hemşirelerin trakeostomi bakımı konusunda teorik ve uygulama bilgilerinin yetersiz olduğu saptanmıştı (16).

Bu çalışmada, yoğun bakım ünitelerinde yatan trakeostomili hastalara bakım veren hemşirelerin deneyimlediği bakım uygulamalarının derinlemesine bireysel görüşmeler ile incelenmesi amaçlanmıştır. Bu çalışmanın sonuçları, mevcut durumun değerlendirilmesine ve bu alandaki gereksinimlerin tanımlanmasına katkı sağlayacağı düşünülmektedir.

\section{GEREÇ VE YÖNTEMLER}

\section{Araştırmanın Tipi}

Bu çalışma Ekim-Kasım 2019 tarihleri arasında nitel araştırma deseninde yapılmıştır. Bu araştırmada "Trakeostomili Hasta Bakımı" kavramı merkeze alınarak nitel (kalitatif) araştırma desenlerinden fenomenolojik yaklaşım kullanıımıştır. Fenomenoloji, gerçekliği bireysel bakış ve deneyimlerde arayan bir akım olarak gelişmiştir. Fenomenoloji, belirli durumlarda insan tecrübelerini anlamak, empatik ve açık bir şekilde bu anlamları iletmeye çalışmak için kullanılır (17).

\section{Katilımcılar}

Araşttrmanın çalışma grubunu Güneydoğu Anadolu bölgesinde bir ilde yer alan bir Üniversite Hastanesi'nin Yoğun Bakım Ünitesi hemşireleri oluşturmuştur. Araştırmanın çalışma grubu amaçlı örneklem türlerinden ölçüt örneklemeye göre belirlenmiştir. Ölçüt örneklemede amaç, araştrmaya dahil edilme ve dışlama kriterlerini karşılayan tüm olguları gözden geçirmek ve incelemektir (18). Bu çalışmaya dahil edilme kriterleri hemşirelerin; 18 yaş ve üzerinde olması, en az 1 yıldır yoğun bakım ünitesinde çalışması, araştırmaya katılmayı kabul etmesi ve iletişim probleminin olmaması'dır. Nitel araştırmalarda belirli bir örneklem sayısı olmadığından (18) görüşmeler kavramlar ve süreçlerin tekrar etmeye başladığı doyum noktasına kadar veri toplanmaya devam edilmiş ve 15 hemşire ile çalışma tamamlanmıştır.

\section{Veri Toplama Araçları}

$\mathrm{Bu}$ çalışmada, veri toplama amacıyla hemşirelere ait tanıtıcı bilgilerin olduğu "Tanıtıcı Bilgi Formu" ve "Yarı Yapılandırılmış Görüşme Formu ve Görüşmeci Gözlem Formu" kullanılmıştır.

Tanıtıcı Bilgi Formu: Yaş, cinsiyet, mezun olunan okul, trakeostomili hastalara bakım verme süresi, trakeostomili hasta bakımı ile ilgili bir yayını/web sayfasını düzenli takip etme durumu ve trakeostomili hasta bakımı ile ilgili daha önce eğitim alma durumuna ilişkin bilgileri sorgulayan 7 sorudan oluşmuştur.

Yarı Yapılandırılmış Görüşme Formu ve Görüşmeci Gözlem Formu: Yarı yapılandırılmış görüşme formu, yoğun bakım hemşirelerinin trakeostomili hasta bakımına ilişkin deneyimlerine yönelik açık uçlu 6 sorudan oluşmuştur (11-16). Yarı yapılandırılmış görüşme soruları konuyla ilgili uzmanlar tarafindan değerlendirilmiş ve uzman görüşleri doğrultusunda forma son hali verilmiştir. Buna göre hemşirelere;

- Çalıştı̆ınız birimde trakeostomili hastanın bakımı ile ilgili takip edilen bir protokol ya da uygulama standardı var mıdır? Varsa açıklayınız?

- Çalıştğııız birimde ameliyat öncesi süreçte trakeostomi açılacak hastanın bakımında yapılan uygulamalar nelerdir? 
- Çalıştı̆̆ıız birimde ameliyat sonrası süreçte trakeostomi açılan hastanın bakımında yapılan uygulamalar nelerdir?

- Çalıştı̆ınız birimde trakeostomili hastanın bakımına ilişkin en çok sorun yaşanan konular nelerdir?

- Çalıştı̆ııız birimde trakeostomili hastaların bakımını geliştirmeye yönelik önerileriniz nelerdir?

- Trakeostomi bakımı ile ilgili eklemek istedikleriniz var mı? soruları yöneltilmiştir. Görüşmeci gözlem formunda ise, görüşülen her bir katılımcıyı gösteren kod numarası (K1, K2, K3....), görüşme tarihi ve saati gibi bilgiler yer almıştır.

\section{Verilerin Toplanması}

Araştırma verileri toplanmadan önce hemşireler çalışma hakkında bilgilendirilerek, çalışmaya katılmak isteyen hemşirelerden yazılı onamları alınmıştır. Görüşmelerde zaman kaybını önlemek ve analizlerin daha sağlıklı yapılabilmesi için ses kaydı yapılmak istendiği ve hemşirelere istedikleri anda ses kaydının kapatılabileceği açıklanmıştı. Ayrıca hemşirelere ses kaydını yalnızca araştırmacının dinleyeceği, başka kişilerle paylaşılmayacağı söylenmiştir. Bu koşulları kabul eden hemşireler ile yapılan görüşmeler ses kayıt cihazına kaydedilmiştir. Araştırma verileri Ocak-Şubat 2020 tarihleri arasında toplanmıştır. Araştırmanın verileri toplanmadan önce fiziki koşulları uygun olan, gözlem ve kaydın uygun koşullarda (katlımcının ve görüşmeyi yapan araştırmacının yüz yüze oturduğu ve fiziki koşulları uygun ortam) yapılabileceği bir görüşme odası düzenlenmiştir. Sorulacak soruların bir listesi, ses kayıt cihazı, (raportör için) not defteri ve kalem veri toplama işleminden önce hazır hale getirilmiştir. Görüşmeler hemşireler ile rahat iletişim kurulabileceği düşünülen sakin bir ortamda ve karşılıklı aynı düzeyde oturularak yüz yüze yapılmıştır. Veriler, derinlemesine görüşme tekniği kullanılarak elde edilmiştir. Katılımcıların görüşleri; gizlilik esasına uyularak ve isimleri verilmeden kodlanarak kaydedilmiştir. Görüşlerin sonunda belirtilen rakamlar ise hemşirelere verilen katılımcı numaralarını ifade etmektedir. Görüşmeler, hemşirelerin verdikleri cevaplara bağlı olarak 20-40 dakika sürmüştür. Veri doygunluğuna ulaşılıncaya kadar veriler toplanmıştır.

\section{Çalışmanın Etik Yönü}

Çalışma öncesinde bir Üniversitenin Biyomedikal Araştırmalar Etik Kurulu'ndan (No:2016/01-02) onay ve ilgili Üniversite Hastanesi Başhekimliği'nden yazılı izin alınmıştır. Hemşirelere çalışmanın amaçları açıklanmış, çalışmaya katıımın gönüllülük ilkesi ile olacağı, verdikleri bilgilerin yalnızca bilimsel amaçla bu çalışmada kullanılacağı ve üçüncü şahıslarla paylaşılmayacağı ve istedikleri zaman çalışmadan ayrılabilecekleri konusunda bilgilendirilme yapılmıs, Helsinki Bildirgesi ve yayın etiğine uyulmuştur. Çalışmaya katılmayı kabul eden hemşirelerin sözlü ve yazılı izinleri alınmıştır.

\section{İstatistiksel Analiz}

Yarı yapılandııılmış görüşmeler yazıya geçirilerek kayıt altına alınmış, sonrasında Microsoft Word programında bilgisayar ortamına aktarılıp tekrar okunarak yazılı hale getirilmiştir. Analizler, Giorgi'nin fenomenolojik yöntem analizi kullanılarak 4 aşamada yapılmıştı. Illk olarak, bütün görüşme raporları metin içeriğini genel anlamda elde etmek için okunmuş ve tekrar kontrol edilmiştir. İkinci olarak, raporlar fenomenolojik küçültme (azaltma) bakış açısı ile yeniden okunmuş ve daha küçük birimlere bölünerek, değiştirme ve dönüştürmeler yoluyla anlamlar oluşturulmuştur. Üçüncü adımda, anlam üniteleri fenomenin anlamları ortaya çıkana kadar daha ileri analiz edilmiş ve yeni anlamlı birimler ortaya çıkarılmıştr. Son adımda ise; anlamlı üniteler, fenomenin özü ve bileşenlerine dönüştürülerek ana tema ve alt temalar oluşturulmuştur.

\section{BULGULAR}

Katılımcıların yaşları 25-42 aralı̆̆ında, 10’u kadın, yoğun bakım hemşiresi olarak çalışma yılı 1-15 yıl olup, tüm katılımcıların lisans mezunu olduğu ve trakeostomili hastaların bakımına ilişkin eğitim aldığı belirlenmiştir. Hemşirelerin hasta güvenliği ile ilgili herhangi bir yayını/web sayfasını düzenli olarak takip etmediği görülmüştür.

Katılımcıların trakeostomili hasta bakımına ilişkin görüşleri 2 ana tema ve 5 alt temadan oluşmaktadır. Ana tema ve alt temalar 1. Trakeostomili Hastanın Bakım Uygulamaları (Protokoller, Trakeostomi Öncesi Hasta Bakımı ve Trakeostomi Sonrası Hasta Bakımı), 2. Bakım Sırasında Yaşanan Sorunlar ve Çözüm Önerileri (Sorun Yaratan Durumlar ve Bakımı Geliştirmeye Yönelik Öneriler)'dir (Tablo 1).

Tablo 1. Katılımcıların trakeostomili hasta bakımına ilişkin görüşleri: ana ve alt temalar

\begin{tabular}{lll}
\hline \multicolumn{2}{l}{ ANA TEMA } & ALT TEMA \\
\hline$>$ Trakeostomili Hastanın Bakım Uygulamaları & $\bullet$ & Protokoller, \\
& $\bullet \quad$ Trakeostomi Öncesi Hasta Bakımı \\
& $\bullet \quad$ Trakeostomi Sonrası Hasta Bakımı \\
\hline Bakım Sırasında Yaşanan Sorunlar ve Çözüm & $\bullet \quad$ Sorun Yaratan Durumlar \\
& $\bullet$ Önerileri & B Bakımı Geliştirmeye Yönelik Öneriler
\end{tabular}




\section{Trakeostomili Hastanın Bakım Uygulamaları}

Trakeostomili Hastanın Bakım Uygulamaları ana teması Protokoller, Trakeostomi Öncesi Hasta Bakımı ve Trakeostomi Sonrası Hasta Bakımı olmak üzere 3 alt temadan oluşmaktadır.

\subsection{Protokoller}

Katılımcıların çoğu 'Çalıştı̆ınız birimde trakeostomili hastanın bakımı ile ilgili takip edilen bir protokol ya da uygulama standardı var mıdır, açıklayınız?' sorusuna cevap olarak ‘6x1 aspirasyon, 24x1 soğuk buhar, 8x1 oksijen satürasyonu takibi, günlük trakeostomi kanül kontrolü, günde en az 1 kez trakeostomi bölgesinin bakımının yapılması ve pansumanının yenilenmesi, tapotman, mobilizasyon uygulaması, beslenmenin sağlanması ve odanın nemlendirilmesi gerektiğini' ifade etmişlerdir.

'Öncelikle, hasta başları yataktan $45-60^{\circ}$ yüksek olacak şekilde takip ediyoruz. Hastalara genellikle $6 \times 1$ aspirasyon yapılıyor, $24 \times 1$ soğuk buhar alması sağlanıyor. Hastanın $8 \times 1$ satürasyon takibi yapılıyor. Trakeostomi yerinin bakım ve pansumanı yenileniyor. Trakeostomi kanülünün de kontrolü günlük yapılıyor. Tapotman yapıyoruz ve erken mobilize etmeye çalışıyoruz hastaları...' (K.1.)

\subsection{Trakeostomi Öncesi Hasta Bakımı}

Katılımcıların çoğu 'Çalıştığınız birimde ameliyat öncesi süreçte trakeostomi açılacak hastanın bakımında yapılan uygulamalar nelerdir?' sorusuna cevap olarak 'trakeostomi açılmasının gerekliliği ve önemi, trakeostomi sonrasında yaşanabilecek olumlu-olumsuz durumlar hakkında hasta ve yakınlarına bilgi verilmesi, yasal hazırlık, ameliyat bölgesinin temizliği, profilaktik ilaçların kullanılması' şeklinde belirtmişlerdir. Dört katılımcı ise ameliyat öncesi süreç hazırlığında psikolojik hazırlık ile ilgili yapılan uygulamaların yetersiz olduğunu da ifade etmiştir. (K.1., K.2., K.4., K.9.)

'...Hastaya ve yakınlarına trakeostomi açılmasının gerekliliği ve önemi hakkında bilgi veriliyor... Hastaya bunun kalıcı veya geçici olduğuna dair bilgi verilir... İşlem öncesi cerrahi onam alınıyor. Profilaktik ilaçlar (antibiyotik, mukolitikler ve antidepresanlar vb.) başlanır. Ancak hastaya (ve yakınlarına) psikolojik destek verilmesi anlamında yetersiz kalındığını düşünüyorum. Bu konuda daha ileri destek sağlanabilir.' (K.8.)

\subsection{Trakeostomi Sonrası Hasta Bakımı}

Katılımcıların çoğu 'Çalıştığınız birimde ameliyat sonrası süreçte trakeostomi açılan hastanın bakımında yapılan uygulamalar nelerdir?' sorusuna cevap olarak 'monitörizasyon, yaşamsal bulgu ve satürasyon takibi, kanül bakımı, aspirasyon, tapotman, mobilizasyon, enfeksiyon ve kanama kontrolü, pansuman, beslenme eğitimi, buhar ve oksijen uygulamasının' yapıldığını belirtmişlerdir. Bir katılımcı ise ameliyat sonrası süreçte iletişim ile ilgili yapılan uygulamaların yetersiz olduğunu da ifade etmiştir. (K.2.)

'Yakın vital ve satürasyon takibi, 24x1 soğuk buhar desteği, 6×1 aspirasyon yapılması, günlük pansuman ve kanül bakımı da yapılıyor... Ekstra olarak oksijen tedavisi yapılıyor... Balgam söktürücü verilir. Trakeostomi bölgesinde kanama olup olmadığı değerlendirilir, havayolunun açık olup olmadığının değerlendirilir ve enfeksiyon önlemleri alınır. Ama bana göre yeterli bir cerrahi bakım verilmiyor, çünkü yetersiz iletişim yani iletişim eksikliği var... Yetersiz hastalar preoperatif dönemde yeteri kadar bilgilendirilmediği için ajite oluyorlar ve adaptasyon problemi yaşıyorlar.' (K.5.)

\section{Bakım Sırasında Yaşanan Sorunlar ve Çözüm Önerileri}

Bakım Sırasında Yaşanan Sorunlar ve Çözüm Önerileri ana teması Sorun Yaratan Durumlar ve Bakımı Geliştirmeye Yönelik Öneriler olmak üzere 2 alt temadan oluşmaktadır.

\subsection{Sorun Yaratan Durumlar}

Katılımcıların çoğu 'Çalıştı̆ınız birimde trakeostomili hastanın bakımına ilişkin en çok sorun yaşanan konular nelerdir?' sorusuna cevap olarak 'psikolojik sorunlar (trakeostomiyi kabullenmeme ve adapte olamama, anksiyete, iletişim problemleri) ve fizyolojik sorunlar (kanülde tıkaç oluşması, aspirasyona bağlı kanama, trakeostomi boşluğunun zamanla gevşemesi)' şeklinde yanıt vermişlerdir.

'En çok yaşanılan sıkıntı hastanın kabullenmemesi... Hastanın uyumsuz ve tepkili davranması yani uyum sürecindeki sorunlar... Maalesef bununla ilgili olarak hemşirelerin bireysel çabaları dışında başka bir destek ya da girişimde bulunulmamakta... Hastanın düzenli buhar almayı reddetmesi, hasta ve yakınlarııın aspirasyona karşı tepki göstermesi, kanülde tkkaç oluşup hastanın nefes alıp-vermede zorlanması da bu süreçte cabası.' (K.4.)

\subsection{Bakımı Geliştirmeye Yönelik Öneriler}

Katılımcıların çoğu 'Çalıştğınız birimde trakeostomili hastaların bakımını geliştirmeye yönelik önerileriniz nelerdir?' sorusuna cevap olarak 'işlem öncesi ve sonrasında profesyonel psikolojik destek sağlanması, hasta ve yakınlarına karşılaşılabilecek sorunlar ile ilgili etkili eğitim yapılması' şeklinde yanıt vermişlerdir. 
'Iş̧lem öncesi ve sonrasında profesyonel psikolojik destek ve yardım sağlanmalıdır. İşlem öncesi eğitim arttrılımalı ve hasta-hasta yakını bilgilendirilmeli... İşlem sonrasında iletişim nasıl sağlanacağı konusunda bilgi verilmeli... Okuma-yazma bilenler için silinebilir yazı tahtası, küçük karton veya benzer bir aparat ile intiyaç/şikayetlerini anlatabileceği hazır kartlar ya da işaretler kullanılmalı.' (K.13.)

\section{TARTIŞMA}

Katılımcıların çoğu çalıştkları birimde trakeostomili hastanın bakımı ile ilgili takip edilen bir protokol ya da uygulama standardı ile ilgili olarak $6 \times 1$ aspirasyon, $24 \times 1$ soğuk buhar, $8 \times 1$ oksijen satürasyonu takibi, $1 \times 1$ trakeostomi kanül kontrolü, 1x1 trakeostomi bölgesinin bakımının yapılması ve pansumanının değiştirilmesi, tapotman, mobilizasyon uygulaması, beslenmenin sağlanması ve odanın nemlendirilmesi uygulamalarını yaptıklarını ifade etmişlerdir. Literatür incelendiğinde, hastaların bakım sürecinde standart bir trakeostomi bakım protokolünün/rehberinin takip edilmesi trakeostomiye bağıı komplikasyonların azalmasını ve bakımın kalitesinin artmasını sağlamaktadır $(20,21)$. Bakım rehberleri ve kaynak kitaplar trakeostomili hastaların hemşirelik bakımında temel olarak trakeostomi aspirasyonu, iç kanül temizliği, kaf bakımı, peristomal cilt bakımı ve nemlendirme uygulaması başlıklarını kapsamaktadır $(9,12,22-24)$. Aspirasyon trakeada biriken fazla sekresyonları temizleyerek trakeostomili hastada hava yolu açıklığını sürdürmek açısından oldukça önemli bir uygulamadır. Aspirasyon işlemi, rutin uygulamalara ek olarak hastada hırıltılı solunum duyulduğunda, hastanın oksijen saturasyonu düştüğünde ve hastada siyanoz görüldüğünde mutlaka uygulanmalıdır $(9,10,25)$. Literatürde, kanül temizliğinin ve peristomal cilt bakımının günde en az iki kez yapılması ve kaf basınıncının sekiz saatte bir kez kontrol edilmesini önerilmektedir $(9,22,26)$. Bu bilgiler ışığında, çalışmamıza katılan hemşirelerin trakeostomili hastalarda hemşirelik bakımını temel düzeyde gerçekleştirdiği ancak yeterli düzeyde bilgiye sahip olmadıkları söylenebilir.

Katılımcıların çoğu çalıştıkları birimde ameliyat öncesi bakım uygulamaları ile ilgili olarak hastayı ve yakınlarını bilgilendirme (trakeostomi açılma nedeni, yaşanabilecek olası durumlar v.b.) yasal hazırlık, ameliyat bölgesinin temizliği ve profilaktik ilaçların kullanılması uygulamalarını sıralamışlardır. Hastalara trakeostomi açılmasının endikasyonları arasında mekanik ventilasyon ilk sırada yer almaktadır ve işlemin mekanik ventilasyon desteğinin ilk 7-10 günü içinde yapılması önerilmektedir $(27,28)$. Literatür incelendiğinde, erken trakeostomi girişiminin uzamış entübasyonun üst havayolunda oluşturduğu hasarı azalttğı, hastanın konuşabilmesine ve yemesine yardımcı olduğu, hemşirelik bakımını kolaylaştırdığı, enfeksiyon oranını azalttğı, yoğun bakım yaţ̧ süresini kısaltthğı ve mortaliteyi azalttığını gösteren çalışmalar bulunmaktadır $(29,30)$. Trakeostomi açılmadan önce hastalara ve yakınlarına bu bilgilerin aktarılması, trakeostomiye bağlı komplikasyonların azaltılması ve yasal olarak onay almak açısından önem teşkil etmektedir (31).

Katılımcıların çoğu çalıştıkları birimde ameliyat sonrası süreçte hastaların bakımı için monitörizasyon, yaşamsal bulgu ve satürasyon takibi, kanül bakımı, aspirasyon, tapotman, mobilizasyon, enfeksiyon ve kanama kontrolü, pansuman, beslenme eğitimi, iletişim eğitimi, buhar ve oksijen uygulamalarını yaptıklarını belirtmişlerdir. Ameliyat sonrası süreçte özellikle uzun süreli trakeostomi bakımında hastaların yeterli ve dengeli beslenmesi, iletişim sürecinin yönetilmesi ve enfeksiyonlardan korunması önemlidir $(12,25)$.Trakeostomi işleminden sonra hastalarda larinks ve farinksin fonksiyonlarındaki azalmaya bağıı ortaya çıkan yutma güçlüğü nedeniyle beslenme sorunları ortaya çıkabilir. Bu nedenle hastanın hemşiresinin trakeostomili hastalarda ilk oral alımından önce ve yutma fonksiyonu tamamıyla düzelinceye kadar belirli aralıklarla hastanın yutma fonksiyonunu değerlendirmesi gerekmektedir (27). Trakeostomili hastaların yeterli sıvı alması (oral/intravenöz yol) sekresyonların incelmesini ve daha kolay aspire edilmesini sağlaması açısından önemlidir $(9,22)$. Trakeostomi işlemi uygulanan hastalarda larinkse doğru itilen hava akımı yeteri kadar sağlanamayacağı için vokal kordlar işlevini yitirir ve bu durumun sonucunda hasta konuşamaz (27). Bu hastaların çeşitli cihazlarla, kağıt-kalem kullandırarak ya da resimli çizelgelerle iletişim kurması sağlanmalıdır. Araştırmamızda hemşireler hastalara beslenme ve iletişim eğitimi verdiklerini belirtmişler ancak bu eğitimlerin değerlendirilmesinden ve sonuçlarından bahsetmemişlerdir.

Katılımcıların çoğu çalıştkları birimde trakeostomili hastanın bakımı ile yaşanılan sorunlarla ilgili olarak psikolojik sorunlar (trakeostomiyi kabullenmeme ve adapte olamama, anksiyete, iletişim problemleri) ve fizyolojik sorunlar (kanülde tıkaç oluşması, aspirasyona bağlı kanama, trakeostomi boşluğunun zamanla gevşemesi) yaşanıldığını söylemişlerdir. Trakeostomi hastalarının bakımına ilişkin çalışmalar çoğunlukla hastaların taburcu olurken/olduktan sonra yaşadığı fizyolojik sorunlara (tüpe bağlı sorunlar, mukus tıkacı, konuşamama, boğaz tahrişi ) odaklanmıştır $(7,32)$. Sınırlı sayıdaki çalışmalarda ise hastaların korku yaşadıkları ve trakeostomi bakımı için gerekli becerileri kazanamamaktan endişeli oldukları raporlanmıştı (33-35). Trakeostomi gibi cerrahi işlemlerden önce hastaların psikolojik hazırlığının önemi bilinmesine karşın, trakeostomi açılacak hastaların kritik durumları nedeni ile psikolojik yönden hazırlanmaya zaman olmadığını belirten çalışmalar mevcuttur $(36,37)$. Çalışmamızda literatürde bazı araştırmaların işaret ettiğine benzer şekilde hastaların fizyolojik sorunlar ile psikolojik sorunlar da yaşadığı ortaya konulmuştur.

Katılımcıların çoğu çalıştkkları birimde trakeostomili hastaların bakımını geliştirmeye yönelik işlem öncesi ve sonrasında profesyonel psikolojik destek sağlanması, hasta ve yakınlarına karşılaşılabilecek sorunlar ile ilgili etkili eğitim yapılmasını önermişlerdir. Literatür incelendiğinde, trakeostomili hastaların bakım kalitesini artırmak ve trakeostomiye bağı sorunları azaltmak için yapılan çalışmalar bulunmaktadır $(20,21,38)$. Çalışmalarda trakeostomi bakımının ekip yaklaşımı ile ele alınması, bakım uygulamalarında tıbbi-cerrahi asepsi ilkelerine uyulması, hemşirelere trakeostomi bakımında güncel veriler doğrultusunda hizmet içi eğitimlerin düzenlenmesi, standart bir bakım protokolünün/rehberinin takip edilmesi önerilmektedir $(13,16,21,31)$. Çalışmamızda hemşireler bu önerilere ek olarak hastaların ve yakınlarının psikolojik açıdan destek almasının önemli olduğunu vurgulamışlardır. 
Hemşirelerin trakeostomili hastanın bakımına ilişkin bilgilerinin temel düzeyde yeterli olup bakım uygulamalarının fizyolojik gereksinimler ile sınırlı kaldığı görülmüştür. Hemşirelerin hastanın ve yakınlarının psikolojik gereksinimlerinin farkında oldukları ancak bu konu ile ilgili hemşirelik uygulamalarının ya hiç yapılmadığı ya da yetersiz kaldığı belirlenmiştir. Ayrıca trakeostomi sonrası hastaların iletişim sorunu ile ilgili yapılan uygulamaların da yetersiz olduğu ve bu durumun hastanın ve yakınlarının trakeostomiye adapte olma durumunu olumsuz yönde etkilediği saptanmıştır.

Hemşireler genel olarak fizyolojik açıdan yeterli bilgiye sahip olsalar da, hastaların psikolojik süreci ile ilgili deneyimlerinden olumsuz etkilendikleri göz önünde bulundurularak psikolojik hazırlığa öncelik verilmesi, hastalara ve yakınlarına trakeostomi bakımını içeren tüm konularda yeterli bilgilendirme yapılması, bakım verenlerin/yakınlarının sürece etkili dahil edilmesi, hemşirelerin bakıma ilişkin klinik deneyimleri ve yaşadıkları güçlükler tartşılarak baş etme mekanizmalarının güçlendirilmesi önerilmektedir.

\section{BILDIRIMLER}

Çıkar Çatışması: Yazarlar arasında çıkar çatışması yoktur.

Finansal Destek: Herhangi bir kurumdan maddi destek alınmamıştır.

Etik Kurul İzni: Çalışma öncesinde bir Üniversitenin Biyomedikal Araştırmalar Etik Kurulu'ndan (No:2016/01-02) onay ve ilgili Üniversite Hastanesi Başhekimliği'nden yazılı izin alınmıştır.

Teşekkür: Araştırmaya katılan tüm hemşirelere katkılarından dolayı teşekkür ederiz.

\section{KAYNAKLAR}

1. Frost EA. Tracing the tracheostomy. Ann Otol Rhinol Laryngol. 1976; 85(1): 618-24. doi: 10.1177/000348947608500509.

2. Eavey R. The history of tracheotomy. In: Myers E, Johnson J, Murry T, editors. Tracheotomy: Airway Management, Communication, and Swallowing. San Diego: Singular; 1998.

3. Batra TK, Tilak MR, Pai E, Verma N, Gupta BK, Yadav G, et al. Increased tracheostomy rates in head and neck cancer surgery during the COVID-19 pandemic. International Journal of Oral Maxillofacial Surgery. 2020; S0901-5027(20)30441-0. doi: 10.1016/j.ijom.2020.12.002.

4. Cramer JD, Evan MG, Johnson BM. Mortality associated with tracheostomy complications in the United States: 2007-2016. The Laryngoscope. 2019; 129 (3): 619-26. doi: 10.1002/lary.27500.

5. Muller RG, Mamidala MP, Smith SH, Smith A, Sheyn A. Incidence, epidemiology, and outcomes of pediatric tracheostomy in the United States from 2000 to 2012. Otolaryngology-Head and Neck Surgery. 2019; 160(2): 332-8. doi: $10.1177 / 0194599818803598$.

6. Watters K, O'Neill M, Zhu H, Graham RJ, Hall M, Berry J. Two-year mortality, complications, and healthcare use in children with medicaid following tracheostomy. The Laryngoscope. 2016; 126(11): 2611-2617.

7. Spataro E, Durakovic N, Kallogjeri D, Nussenbaum B. Complications and 30-day hospital readmission rates of patients undergoing tracheostomy: A prospective analysis. The Laryngoscope. 2017; 127(12): 2746-2753. doi: 10.1002/lary.26668.

8. Altınbaş Y, Karaca T. Peristomal Cilt Problemleri: Sistematik Literatür Inceleme. STED. 2018; 27(2): 107-117.

9. Potter PA, Perry AG, Hall A, Stockert PA. Fundamentals of nursing. 7th ed. USA: Mosby; 2009.

10. McGrath BA, Wallace S, Lynch J, Bonvento B, Coe B, Owen A, Cameron T. Improving tracheostomy care in the United Kingdom: results of a guided quality improvement programme in 20 diverse hospitals. British Journal of Anaesthesia. 2020; doi: 10.1016/j.bja.2020.04.064.

11. Sandler ML, Ayele N, Ncogoza I, Blanchette S, Munhall DS, Marques B, Nuss RC. Improving tracheostomy care in resourcelimited settings. Annals of Otology, Rhinology \& Laryngology. 2020; 129(2): 181-190. doi: 10.1177/0003489419882972.

12. Karaca T. Nursing care of the patients with tracheostomy. Journal of Human Sciences. 2015; 12(2): 1078-1091. doi: 10.14687/ijhs.v12i2.3320.

13. Seyman ÇC, Çelik SŞ. Trakeostomili hastalarda yaşam kalitesi ve hemşirelik bakımı. Hacettepe Üniversitesi Hemşirelik Fakültesi Dergisi. 2019; 6(1): 59-64. doi: 10.31125/hunhemsire.544140.

14. McDonough K, Crimlisk J, Nicholas P, Cabral H, Quinn EK, Jalisi, S. Standardizing nurse training strategies to improve knowledge and self-efficacy with tracheostomy and laryngectomy care. Applied Nursing Research. 2016; 32: 212-216. doi: 10.1016/j.apnr.2016.08.003. 
15. El-Gawab, HM. Quality of nursing care on patients with tracheostomy. Port Said Scientific Journal of Nursing. 2017; 4(1): 202-216. doi: 10.21608/PSSJN.2017.33096.

16. Mungan I, Kazancı D, Bektaş Ş, Sarı S, Çavuş M, Turan S. The evaluation of nurses' knowledge related to tracheostomy care in tertiary intensive care units. International Medicine. 2019; 1(6): 313-318. doi: 10.5455/im.54258.

17. Ersoy AF. Fenomenoloji. 3. Baskı. Saban A, Ersoy A, editörler, Eğitimde nitel araştırma desenleri; 2019; Ankara. Anı Yayıncılık; 81-138.

18. Leininger M. Qualitative research methods in nursing. USA: Greyden Pres; 1998.

19. Giorgi A, Giorgi B. Phenomenology. In J. A. Smith (Ed.), Qualitative psychology: A practical guide to research methods. London: Sage Publications. 2003; 25-50.20. Heyd CP, Desiato VM, Nguyen SA, O’Rourke AK, Clemmens CS, Awad MI. Tracheostomy protocols during COViD-19 pandemic. Head \& neck. 2020; 42(6): 1297-1302. doi: 10.1002/hed.26192.

20. Rovira A, Dawson D, Walker A, Tornari C, Dinham A, Foden N, et al. Tracheostomy care and decannulation during the COViD-19 pandemic. A multidisciplinary clinical practice guideline. European Archives of Oto-Rhino-Laryngology. 2020; 1-9. doi: 10.1007/s00405-020-06126-0.

21. Berman A, Synder S, Kozier B, Erb G. Fundamentals of nursing. 8th ed. USA: Mosby; 2012.

22. Harkreader H, Hogan MA, Thobaben M. Fundamentals of nursing. 3th ed. USA: Mosby; 2007.

23. Seyman ÇC, Çelik SŞ. Effect of protective cover on the quality of life of patients with tracheostomy -A Quasi-Experimental Study. Journal of Peri Anesthesia Nursing. 2020; 35(4): 430-436. doi: 10.1016/j.jopan.2020.01.013.

24. Dawson D. Essential principles: tracheostomy care in the adult patient. British Association of Critical Care Nurses. 2014 19 (2): 63-72. doi: 10.1111/nicc.12076.

25. Karaca T, Korkmaz FA. Quasi-experimental study to explore the effect of barrier cream on the peristomal skin of patients with a tracheostomy. Ostomy/wound management. 2018; 64(3): 32-39. doi: 10.25270/owm.2018.3.3239.

26. Black MJ, Hawks JH. Medical-surgical nursing. 8th ed. USA: Saunders; 2009.

27. Gomes-Silva BN, Andriolo RB, Saconato H, Atallah AN, Valente O. Early versus late tracheostomy for critically ill patients. Cochrane Database Systematic Review. 2012; 14(3): doi: 10.1002/14651858.CD007271.pub3.

28. Herritt B, Chaudhuri D, Thavorn K, Kubelik D, Kyeremanteng K. Early vs. late tracheostomy in intensive care settings: Impact on ICU and hospital costs. Journal of Critical Care. 2018; 44: 285- 288. doi: 10.1016/j.jcrc.2017.11.037.

29. Siempos II, Ntaidou TK, Filippidis FT, Choi AMK. Effect of early versus late or no tracheostomy on mortality and pneumonia of critically ill patients receiving mechanical ventilation: a systematic review and metaanalysis. Lancet Respir Med 2015; 3(2): 150-158. doi: 10.1016/S2213-2600(15)00007-7.

30.Aygencel G, Kemaloğlu YK. COViD-19 olan yoğun bakım hastalarında trakeostomi uygulamaları. Kulak Burun Boğaz ve Baş Boyun Cerrahisi Dergisi. 2020; 28(Suppl): 84-89. doi: 10.24179/kbbbbc.2020-76492.

31. Garner JM, Moyle MS, Franzese CB. Adult outpatient tracheostomy care: practices and perspectives. OtolaryngologyHead and Neck Surgery. 2007; 136(2), 301-306. doi: 10.1016/j.otohns.2006.08.023.

32. Sherlock ZV, Wilson JA, Exley C. Tracheostomy in the acute setting: patient experience and information needs. Journal of Critical care. 2009; 24(4): 501-507. doi: 10.1016/j.jcrc.2008.10.007.

33. Nakarada-Kordic I, Patterson N, Wrapson J, Reay SD. A systematic review of patient and caregiver experiences with a tracheostomy. The Patient-Patient-Centered Outcomes Research. 2018; 11(2): 175-191. doi: 10.1007/s40271-017-0277-1.

34. Karaca T, Altinbas Y, Aslan S. Tracheostomy care education and its effect on knowledge and burden of caregivers of elderly patients: a quasi-experimental study. Scandinavian Journal of Caring Sciences. 2019; 33(4): 878-884. doi: 10.1111/ scs.12684.

35. Barnett M. Adapting to living with a tracheostomy. Journal of Community Nursing. 2006; 20(1): 4.

36. Laakso K, Markström A, Havstam C, Idvall M, Hartelius L. Communicating with individuals receiving home mechanical ventilation: the experiences of key communication partners. Disability and Rehabilitation. 2014; 36(11): 875-883. doi: 10.3109/09638288.2013.822572.

37. Masood MM, Farquhar DR, Biancaniello C, Hackman TG. Association of standardized tracheostomy care protocol implementation and reinforcement with the prevention of life-threatening respiratory events. JAMA Otolaryngology-Head \& Neck Surgery. 2018; 144(6): 527-532. doi: 10.1001/jamaoto.2018.0484. 